\title{
Dengue fever associated with acute scrotal oedema
}

\author{
*K Jagadish Kumar ${ }^{1}$, B Nataraj ${ }^{2}$, C Anitha ${ }^{3}$, M Santhoshkumar ${ }^{4}$
}

Sri Lanka Journal of Child Health, 2015; 44(3): 176-177

(Key words: Dengue, acute idiopathic scrotal oedema)

\section{Case report}

A 10-year-old boy presented with fever since 7 days, headache and body aches since 3 days. Examination revealed stable vitals, facial flushing and puffiness and soft tender hepatomegaly. The haemoglobin level was $10.8 \mathrm{~g} / \mathrm{dl}$, total leucocyte count $8,200 / \mathrm{cu} \mathrm{mm}$, haematocrit $37 \%$ and platelet count $214,000 / \mathrm{cu} \mathrm{mm}$. His platelet counts started dropping down day by day to reach a nadir of $17,000 / \mathrm{cu} \mathrm{mm}$. He developed hypotension during the course and was managed with intravenous Ringer lactate. His blood and urine cultures were sterile. He was positive for Dengue NS1 antigen and IgM anti dengue antibodies by ELISA. His Widal test, Weil-Felix and peripheral smear for malarial parasite were negative. His kidney function tests were normal. Ultrasonography revealed a $3.5 \mathrm{~mm}$ gall bladder wall thickening with pericholecystic fluid, ascites and right pleural effusion. He became afebrile on the $4^{\text {th }}$ day of admission and developed bilateral non tender, erythematous scrotal swelling (Figure $1 \mathrm{~A}$ ).

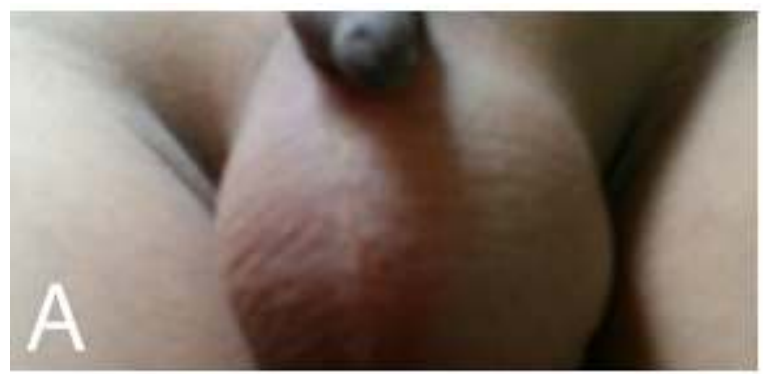

Figure 1 A: Erythema and swelling of the scrotum

On the same day his platelet count was $25,000 / \mathrm{cu}$ $\mathrm{mm}$. Sonography revealed $5 \mathrm{~mm}$ bilateral scrotal wall thickening due to oedema (Figure $1 \mathrm{~B}$ ), bilateral

${ }^{1}$ Professor of Paediatrics, ${ }^{2}$ Assistant Professor of Radiodiagnosis, ${ }^{3}$ Associate Professor of Paediatrics, ${ }^{4}$ Assistant Professor of Pediatrics, JSS Medical College, JSS University, Mysore, India

*Correspondence: jagdishmandya@gmail.com
(Received on 10 July 2014: Accepted after revision on 22 August 2014)

hydrocele, more on the left side with oedematous enlarged left epididymis measuring $11 \times 6 \mathrm{~mm}$ and right epididymis measuring $7 \times 4 \mathrm{~mm}$. Both testes were normal in size and vascularity. His scrotal swelling subsided within 3 days, platelets count became normal and he was discharged.

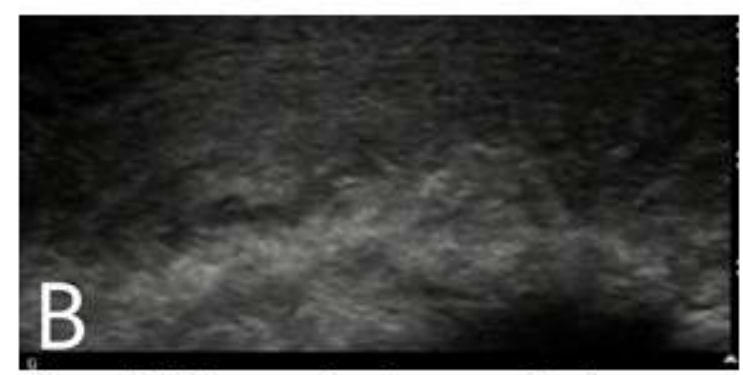

Figure 1 B: Sonography of scrotum showing marked thickening of scrotal wall, indicating oedema

\section{Discussion}

The differential diagnosis of scrotal swellings in children includes epididymoorchitis, testicular torsion, incarcerated inguinal hernia and trauma that requires emergency surgical intervention whereas hydroceles and acute idiopathic scrotal edema (AISE) do not need such intervention. AISE is defined as a self-limiting oedema and erythema of the scrotum that usually affects boys between the ages of 5 and 11 years and resolves without sequelae in 1-3 days ${ }^{1,2}$. AISE is one of the important differential diagnoses in children presenting with an acute scrotum and it accounts for $20-30 \%$ of acute scrotal disorders ${ }^{1}$. They are asymptomatic or complain of minimal scrotal discomfort ${ }^{1}$. Acute scrotal swelling associated with dengue fever is a rare and self-limiting condition, which resolves in a few days without any complications $^{1,3}$. Authors diagnosed the scrotal swelling in dengue fever as AISE and attributed the cause as a leakage from increased vascular permeability due to dengue haemorrhagic fever and 
as an inflammatory response triggered by inflammatory mediators reacting to dengue viral antigen $^{1,3}$. The specific sonographic findings for AISE include thickening and oedema of the scrotal wall and hyperaemia of the scrotum along with normal appearance of the testicles ${ }^{2,4,5}$. Lee et al detected bilateral scrotal wall oedema in 9 out of 12 cases [mean wall oedema was $11.2 \mathrm{~mm}(4-20.7 \mathrm{~mm})$ ] and one had prominent epididymis. ${ }^{4}$. However hydrocele (most likely reactive) and prominent epididymis have also been observed along with typical scrotal wall findings in various studies and similar sonographic findings were detected in our child too ${ }^{2,4,5}$. Sonography is the modality of choice in all cases of acute scrotum ${ }^{2,4}$. Our child is a case of AISE, who developed acute scrotal swelling during the course of dengue haemorrhagic fever with consistent sonographic findings and resolved without sequelae in 3 days. To conclude, even though AISE is rare in dengue infection, detailed clinical examination and scrotal sonography should be done to avoid unnecessary surgical exploration in children who presents with acute scrotal swelling.

\section{References}

1. Chen TC, Lu PL, Chen YH, Tsai JJ, Chen TP. Dengue haemorrhagic fever complicated with acute idiopathic scrotal oedema and polyneuropathy. American Journal of Tropical Medicine and Hygiene 2008; 78: 810.

PMid: 18187776
2. Geiger J, Epelman M, Darge K. The Fountain Sign: A novel colour Doppler sonographic finding for the diagnosis of acute idiopathic scrotal oedema. Journal of Ultrasound in Medicine 2010; 29:1233-7. PMid: 20660458

3. Shamim M, Gulzar Naqvi S Z. Dengue fever associated with acute scrotal oedema: two case reports Journal of the Pakistan Medical Association 2011; 61:601-4.

PMid: 22204221

4. Lee A, Park SJ, Lee HK, Hong HS, Lee BH, Kim DH. Acute idiopathic scrotal oedema: ultrasonographic findings at an emergency unit. European Radiology 2009; 19: 207580.

http://dx.doi.org/10.1007/s00330-009-1356Z

PMid: 19259680

5. Klin B, Lotan G, Efrati Y, Zlotkevich L, Strauss S. Acute idiopathic scrotal oedema in children -revisited. Journal of Pediatric Surgery 2002; 37: 1200-1202. http://dx.doi.org/10.1053/jpsu.2002.34472 PMid: 12149702 